\title{
ASSOCIATIVE REFERENCE MODEL IN THE STATISTICAL THEORY OF IONIC-AQUEOUS SOLUTIONS
}

\author{
M.F.HolOVKo, O.P.ANTONEVYCH \\ Institute for Condensed Matter Physics \\ Ukrainian National Academy of Sciences \\ 1 Svientsitskii St., 290011 Lviv, Ukraine
}

Received September 12, 1995

\begin{abstract}
A new reference model for ionic-aqueous solution is proposed. We consider a three component hard sphere mixture. One of the species corresponds to water molecules and includes four short-range attractive sites, simulating the creation of hydrogen bonds in water. Other components correspond to cations and anions and contain one attractive site, which supposes dimerization between them. The special kind of association between ions and molecules is used for the description of solvation effects. We suppose, that each site of water molecules can be only singly bound with ions and each ion can be bonded with many water sites. The possible number of solvation bonds, that can be established with the same ions is restricted only by the relationships between the species diameter. The expression for the unbonded site concentrations, free energy, and pressure have been obtained. The phase transition of gas - $H$-bonds network type, which arises in the model under consideration for pure water, disappears with increasing of ion fraction.
\end{abstract}

\section{Introduction.}

Associative fluids with strong short-range and orientationally dependent interaction have been a subject of current interest for at least a decade. Such a situation we have in the case of water, aqueous solution, high valence electrolytes and so on. In this case a wide range of theories, based on single density expansions gives unsatisfactory results $[1,2]$, especially when the strength of association and solvation interactions is increased. An infinite number of terms in this expansion should be included in order to reproduce the correct low density limit for strongly associating liquids. As it was shown in $[3,4]$ this problem occured due to the creation of dimers and higher s-mer complexes, caused by the short-range highly attractive interaction.

The starting point of the modern liquid theory is the separation of the interparticle potential $U_{x y}(1,2)$ into a sum of two different terms [5]

$$
U_{x y}(1,2)=U_{x y}^{R}(1,2)+U_{x y}^{L}(1,2),
$$

where $U_{x y}^{R}(1,2)$ and $U_{x y}^{L}(1,2)$ are the short and the long range parts of the total potential, respectively. The subscripts $x y$ denote the particle species. 
The short-range part is of great importance in the description of the liquid structure. It is considered to be a reference system. The model of hard spheres (HS) can be used as a reference system for the simple liquids. But in the case of associative liquids we should include into the reference part both the hard sphere interaction and the short range associative attraction, which is responsible for association and solvation effects. Such a description of the short range attraction is possible in the framework of the recently developed multidensity formalism $[3,4,6]$. In the above formalism the statistical thermodynamics is reformulated in terms of additional density parameters. Those parameters could be regarded as the densities of unbonded, once-, twice- and many times bonded particles.

The model of water proposed by Nezbeda and co-workers $[7,8]$ could be regarded as an undoubted success of the associative approach. In the framework of this model a water molecule is modelled by a hard sphere, that includes four tetrahedrally arranged sites. An attraction between them leads to the creation of the $H$-bonds network among water molecules, characteristic of aqueous systems. Recently a generalization of this model to the case of an aqueous electrolyte solution has been proposed [9]. The associative reference model of ionic-aqueous solution includes besides the water molecules the ions, modelled by hard spheres containing one attractive site. This model takes into account all important properties of aqueous electrolyte solution: the presence of $H$-bonds network, ions dimerising and solvation effects. However solvation effects were modelled as the dimer formation of water molecules and ions attraction sites. Though, the model gives good description for pure water and pure ions cases, it does not provide good solvation effects description, if the concentration of ions is low. That is why only one water molecule can be bonded with the certain ion. More explicit description of the solvation effects can be performed in the framework of the model, recently proposed [10] as a reference system for the highly asymmetric electrolyte solutions. For this purpose we will use the special type of association between ions and water molecules: each site of water molecules can be only singly bonded with an ion and an ion can be bonded with many water sites. The mean number of water-ion bonds per ion depends on the relation between water molecule and ion diameters, that ensures the realistic value of solvation coordination number of ions. Our purpose is to study the properties of this model.

\section{Model and theory.}

In this work we consider the reference system for a three-component mixture of water molecules, positive and negative ions. This model of water as well as the Kolafa-Nezbeda model [8] is qualitatively similar to the ST2 model. Each water molecule is modelled by a hard sphere (representing the oxygen atom) of diameter $\sigma_{w}$ with four interaction sites of two kinds, $H$-sites and $O$-sites, arranged with the tetrahedral geometry. Two $H$-sites (hydrogen-sites) are located directly on the surface of the sphere while the $O$-sites (simulating the lone electron pair) are submerged by $\sigma_{w} / 20$ under the surface. The hydrogen bonding is modelled by the square-well attraction between the $H$ - and $O$-sites, whereas there is no interaction between the identical sites.

In the framework of our model, the ions are described by hard spheres of diameters $\sigma_{p}$ and $\sigma_{n}$ (representing the positive and negative ions) with attractive sites in the centers of them. These sites allow us to consider the many-to-one water-ion interaction and in such a way to take the solvation 

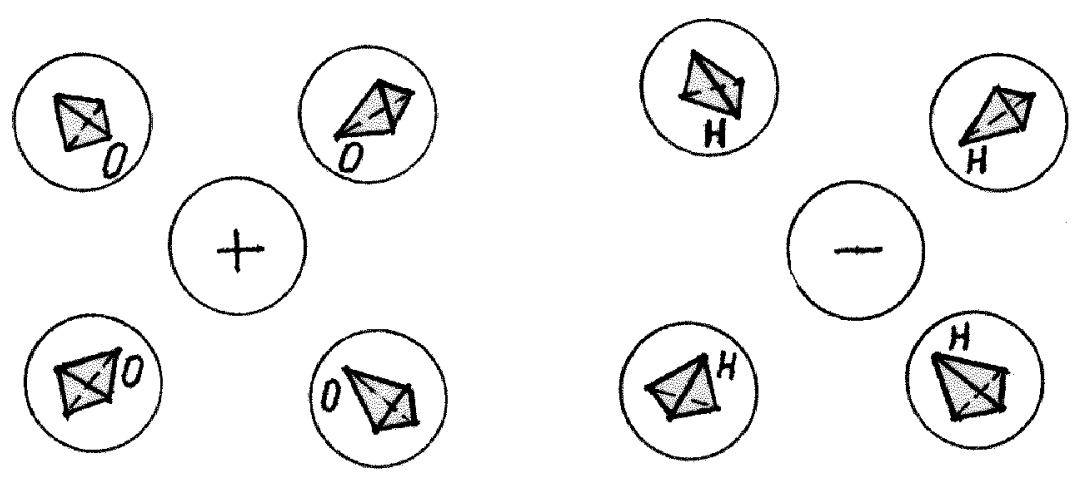

Figure 1. Shematic representation for the model of ionic-aqueous solution.

effects into account. Besides that, we assume the possibility of the interionic dimerization to exist. The latter is modelled by the square-well attraction between ions with different "signs".

In order to describe the associative interaction more accurately we propose here an approximate expansion of the intersite potential into quadratic wells (classical harmonic oscillators) which leads to simple Gaussian integrals:

$$
\Phi_{i j}\left(z_{i j}\right)= \begin{cases}U_{0 i j}+U_{1 i j}\left(z_{i j}-z_{0 i j}\right)^{2} & , z_{i j}<l_{i j} \\ 0 & , z_{i j}>l_{i j}\end{cases}
$$

Here

$$
i, j \in \Gamma \equiv\left\{\ldots \cup \Gamma_{x} \cup \Gamma_{y} \cup \ldots\right\},
$$

$\Gamma_{x}$ is a set of the sites in molecule of the species $x$. In this paper the indices $\alpha=(a, b, c)$ are used to denote ionic sites, the indices $\beta=(s, t, u)$ are used to denote water molecule sites, the indices $x, y, w$ are used to denote both species. $z_{i j}$ is the distance between the sites, $l_{i j}=l_{i}+l_{j}, l_{i}$ is the cut-off radius of the site attraction, $U_{0}, U_{1}$ are coefficients of the expansion of the site-site interaction potential near its minimum at $z=z_{0}$ into the Taylor series.

We assume, that the coupling between two water sites gets saturation, when an interaction between them arises, so any other site can not reach the interaction region. This condition could be ensured by the proper choice of the associative interaction cut-off radius $l_{i}$, distance $d_{i}$ between a site and a sphere center and hard sphere diameter $\sigma_{i}$

$$
\begin{gathered}
L_{i j} \geq 0, \quad L_{i j}=l_{i j}+d_{i}+d_{j}-\sigma_{i j} ; \\
\sqrt{\sigma_{i k}^{2}+d_{i}{ }^{2}-2\left(I_{1} I_{2}+I_{3} I_{4}\right)}>d_{k}+l_{i k},
\end{gathered}
$$

where $L_{i j}$ is the width of the potential well, index $k$ denotes the third molecule trying to approach the i-site;

$$
I_{1}=\frac{\sqrt{\left(2 \sigma_{i j}+\sigma_{k}\right) \sigma_{i} \sigma_{j} \sigma_{k}}}{2 \sigma_{i j}},
$$




$$
\begin{gathered}
I_{2}=\frac{2 \sqrt{\left(L_{i j}+2 \sigma_{i j}\right)\left(L_{i j}+2 \sigma_{i j}-d_{i}\right)\left(d_{i}+\sigma_{i j}\right)\left(L_{i j} \sigma_{i j}\right)}}{\sigma_{i j}}, \\
I_{3}=\sqrt{\sigma_{i j}{ }^{2}-I_{1}^{2}}, \\
I_{4}=\sqrt{{d_{i}}^{2}-I_{2}^{2}} .
\end{gathered}
$$

So, the potential model, employed here can be presented in the form

$$
U_{x y}(r)=U_{x y}^{H S}(r)+\Phi_{x y}^{11}(z)+\delta_{\alpha, x} \delta_{\beta, y} U_{x y}^{01}(l)+\delta_{\alpha, y} \delta_{\beta, x} U_{x y}^{10}(l),
$$

where $U_{x y}^{H S}(r)$ is the potential of the hard spheres of diameters $\sigma_{x}$ and $\sigma_{y}$ at a distance $\mathrm{r} ; \Phi_{x y}^{11}(z)$ is the associative potential between the water sites; $U_{x y}^{01}(l)$ is the depth of the associative potential well between ionic and water sites.

The mole fraction of unbonded sites is defined by the following relation:

$$
1=x_{i}+\sum_{j \in \Gamma} \rho_{j} x_{i} x_{j}\left(\Delta_{i j}^{11}+\delta_{\beta, i} \delta_{\alpha, j} \Delta_{i j}^{10}\right),
$$

where $x_{i}=\rho_{i}^{0} / \rho_{i}, \rho_{i}$ is the number density of $i$-sites, while $\rho_{i}^{0}$ is the number density of unbonded $i$-sites;

$$
\begin{gathered}
\Delta_{i j}^{11}=\int g^{00}(1,2) F_{i j}(1,2) d \vec{r}_{i j} d \Omega_{i} d \Omega_{j}, \\
F_{i j}=\left(e^{-\beta U_{i j}}-1\right) .
\end{gathered}
$$

$g_{2}^{00}(1,2)$ is unbonded part of pair correlation function. We assume, that $g^{00}(1,2)$ is constant in the small region $l_{i j}$. Then we can replace $g^{00}(1,2)$ by its contact value $g_{x y}^{00}\left(\sigma_{x y}+\right)$ :

$$
\Delta_{i j}^{11}=g_{x y}^{00}\left(\sigma_{x y}+\right) \int F_{i j}(1,2) d \vec{r}_{i j} d \Omega_{i} d \Omega_{j}=g_{x y}^{00}\left(\sigma_{x y}+\right) K_{i j},
$$

where $K_{i j}$ is the orientationally averaged volume, available for bonding multiplied by -Mayer $F_{i j}$-function(2.12)). The formulae for $K_{i j}$ for quadratic and square wells are given in the appendix.

The formula for the contact values of $g_{x y}^{00}\left(\sigma_{x y}+\right)$ were taken from [10]:

$$
g_{2 x}^{00}\left(\sigma_{x y}+\right)=g_{2}^{H S}{ }_{x y}\left(\sigma_{x y}+\right)\left(1-\frac{\sum_{u} \chi_{u y} M_{x y}^{u}}{1+\sum_{u} \chi_{u y}}-\frac{\sum_{u} M_{y x}^{u} \chi_{x u}}{1+\sum_{u} \chi_{x u}}\right),
$$

where $u \epsilon\left\{\ldots \cup \Gamma_{s} \cup \Gamma_{t} \cup \ldots\right\}, \Gamma_{s}$ - is the set of the molecular sites in a molecule of the species $s$;

$$
\chi_{u y}=\frac{\rho_{u} x_{u} \sigma_{u}^{2} K^{u y} \delta_{\alpha, y}}{4(1-\eta) \sigma_{u y}^{2}}
$$




$$
\chi_{x u}=\frac{\rho_{u} x_{u} \sigma_{u}^{2} K^{x u} \delta_{\alpha, x}}{4(1-\eta) \sigma_{x u}^{2}}
$$

where

$\rho_{u}$ - is the number density of the species with $u$-sites;

$x_{u}$ is the mole fraction of unbonded $u$-sites;

$\sigma_{u}$ is the diameter of molecules with $u$-sites;

$\sigma_{x y}=\left(\sigma_{x}+\sigma_{y}\right) / 2$

$\delta_{\alpha, x}$ is the Kronecker delta;

$$
M_{x y}^{u}=\frac{\sigma_{x} \sigma_{u y} g_{u y}^{H S}\left(\sigma_{u y}+\right)}{\sigma_{u} \sigma_{x y} g_{x y}^{H S}\left(\sigma_{x y}+\right)} ;
$$

$g_{x y}^{H S}\left(\sigma_{x y}+\right)$ is the contact value of the pair correlation function for hard spheres.

Let us consider the formula (2.14). We can see, that only water-water contact values of distribution functions coincide with those given by the hard spheres model. The contact values for ion-ion and ion-water distribution functions depend on concentrations of unbonded water sites. Restricting ourselves to the case of the three-component water-ionic mixture we obtain:

$$
\left\{\begin{array}{l}
1=x^{O}+2 \rho_{w} x^{O} x^{H} \Delta^{O H}+\rho_{p} x^{O} \Delta^{O p} x^{p} \\
1=x^{H}+2 \rho_{w} x^{O} x^{H} \Delta^{O H}+\rho_{n} x^{H} \Delta^{H n} x^{n} \\
1=x^{p}+\rho_{n} x^{p} \Delta^{p n} x^{n} \\
1=x^{n}+\rho_{p} x^{n} \Delta^{p n} x^{p} .
\end{array}\right.
$$

Here

$$
\begin{gathered}
\Delta_{O H}^{11}=g_{w w}^{H S}\left(\sigma_{w w}+\right) K_{O H} \\
\Delta_{p O}^{11}=\Delta_{H n}^{11}=0 \\
\Delta_{p O}^{10}=\Delta_{p O}^{10}\left(x_{O}\right)=\frac{g_{w p}^{H S}\left(\sigma_{w p}+\right) K_{p O}}{2 \chi_{p O}} \\
\Delta_{H n}^{10}=\Delta_{H n}^{10}\left(x_{H}\right)=\frac{g_{w n}^{H S}\left(\sigma_{w n}+\right) K_{H n}}{2 \chi_{H n}} \\
\Delta_{p n}^{11}=\Delta_{p n}^{11}\left(x_{O}, x_{H}\right)=g_{p n}^{H S}\left(\sigma_{p n}+\right) K_{p n}\left(1-\frac{2 \chi_{H n} M_{p n}^{H}}{1+2 \chi_{H n}}-\frac{2 \chi_{p O} M_{n p}^{O}}{1+2 \chi_{p O}}\right) .
\end{gathered}
$$

Solving the nonlinear combined equation (2.18) we obtain the concentrations of unbonded sites. Finally, the free energy and pressure can be gained by generalizing of the Wertheim theory to mixtures of associating molecules:

$$
\begin{aligned}
& \frac{\beta\left(A-A^{H S}\right)}{N}=\sum_{i \in \Gamma} X^{i}\left(\ln x^{i}-\frac{x^{i}}{2}+\frac{1}{2}\right) . \\
& \beta\left(P-P^{H S}\right)=\rho^{2} \sum_{i \in \Gamma} X^{i}\left(\frac{1}{x^{i}}-\frac{1}{2}\right) \frac{\partial x^{i}}{\partial \rho},
\end{aligned}
$$


where $X^{i}=\frac{N^{i}}{N}$ is the mole fraction of $i$-sites; N- the number of particles in the mixture

$$
N=N_{w}+N_{p}+N_{n}
$$

Investigation of thermodynamic properties of an aqueous electrolyte solution was performed on the basis of obtained formulae. Physically reasonable values were assumed for all the mixture parameters. The concentrations of unbonded sites and pressure were calculated. In the limit of infinite dilution we can get the results for pure water or molten salts.

\section{Results and discussion.}

The model of three - species mixture has been investigated for the components with an equal diameters $\sigma=\sigma_{w}=\sigma_{p}=\sigma_{n}=2.85 \AA$. Such parameters are close to those of $\mathrm{CsCl}$ aqueous solution of [11]. For the sake of simplicity let us neglect the second term in the expansion (2.1). The parameter of the first term in (2.1) that denotes the depth of the potential well is equal to $U_{o w w}^{O H}=-12.9 \mathrm{KT}$ for the interaction of a lone electron pair with a proton. The parameters for the lone electron pair-cation, proton-anion and cation-anion interactions are equal to:

$$
U_{o p w} / U_{o w w}=1.3, \quad U_{o n w} / U_{o w w}=1.025, \quad U_{o p n} / U_{o w w}=1.54,
$$

where $K$ is the Boltzmann constant. The model was investigated at $T=$ $298 \mathrm{~K}$. The cut-off site attraction radius is the same for all sites: $l_{i}=0.075 \sigma$. In order to prevent the creation of ions thrimers and higher s-mers, ion sites are chosen to be submerged by $0.065 \sigma$ under the surface. Then the values $K_{i j} / \sigma^{3}$ are equal to:

$$
\begin{aligned}
& K^{O H} / \sigma_{w w}^{3}=K^{H n} / \sigma_{w w}^{3} \approx 1, \\
& K^{O p} / \sigma_{w w}^{3} \approx 2, \quad K^{p n} / \sigma_{w w}^{3} \approx 10 .
\end{aligned}
$$

The investigation of the mixture calls for calculating the concentration of unbonded sites, by solving the combined equation (2.18). The latter (2.18) was solved by the Newton-Raphson method. At the calculation of contact values $g_{x y}(\sigma)$ we found out, that $g_{p n}^{00}$ becomes negative, when the concentration of unbonded ions is low. This result leads to physically wrong values of the concentrations of unbonded ion sites $\left(x_{i o n s}^{u n b}\right.$ becomes greater than 1$)$. This problem is caused by using of the PY approximation. Such results should not arise in the exponential approximation (for example hypernetted chain approximation (HNC)). In the range of low ionic concentration the value of ion-ion distribution function within HNC approximation falls to zero. In order to correct the unrealistic results, obtained in the PY approximation, we have redefined the formula $(2.23)$ :

$$
\Delta_{p n}^{11}= \begin{cases}0 & , \Delta_{p n}^{11} \leq 0 \\ \Delta_{p n}^{11} & , \Delta_{p n}^{11}>0\end{cases}
$$

This redefining leads to the discontinuous change of pressure at the point of inflection of the distribution function (in the point the ion-ion 
distribution function becomes zero). Using of the HNC approximation gives distribution function without cusp. We have introduced ad hoc smoothing of the inflection point by the seventh-order polynomial under condition that the first and second derivatives are continuous in the vicinity of the point of inflection. Such smoothing solves the problems which arise at the derivation of distribution function in the equation of state (2.25) The results for $g_{p n}^{00}$ are shown in figure 2 .
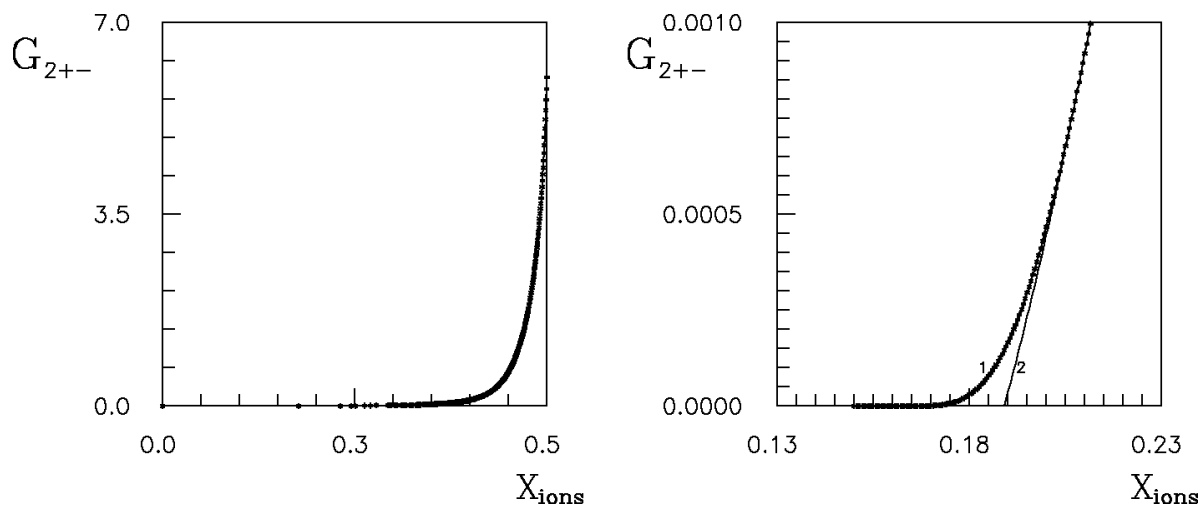

Figure 2. The dependence of contact value of pair correlation function on mole fraction of ions in the mixture. Since all ions are fully clung by water-molecules, then $g_{2 p n}=$ 0 for the low ion fraction. The right figure presents an enlarged view of the smoothing (asterisk curve) of the area, where $g_{2 p n}$ becomes 0 . The solid line exhibits the curve with the cusp which needs smoothing.

The solutions of equation set (2.18) are plotted against the mole fraction of ions $X_{\text {ions }}$ in figure 3 . Obtained behaviour is determined by a number of competing processes:

a) increasing of unbonded $\mathrm{O}$ - and $\mathrm{H}$-sites due to the replacement of ions sites by water sites;

b) decreasing of unbonded O- and H-sites due to the "clinging" of ions by water molecules;

c) the process of ions dimerization, that decreases the free for ion-water interaction ions surface, and so increases the number of unbonded $\mathrm{O}$ - and H-sites.

Let us notice, that redefining (3.3) in the region of the low ions concentration leads to physically reasonable results: $x_{p}=x_{n}=1$, when the concentration of ions is low (up to 0.2). There is no ions dimerization in the system. We can split this region into two parts. In the part with lower ions concentration there is too much free water sites within the ions reach. Each ion is fully clung by water molecules. Some water sites remain unbonded. In the second part the ion number is high enough to create the bond with any free water-site. Nevertheless each ion is still clung by the water molecules, so it can not directly interact with any other ion (there is no ion dimers yet). When the concentration of ions is high ion dimerization effects influence on the concentration of unbonded water-sites. The increasing of the ion dimer number leads to the decreasing of the surface area free for solvation. This rise to the increasing of the unbonded water site concentrations. 
In figures 4 and 5 the dependencies of unbonded ion sites and $g_{2_{p n}}^{00}\left(\sigma_{p n}+\right)$ on $1 / \eta$ ( $\eta$ - packing factor) are presented. The results are in full agreement
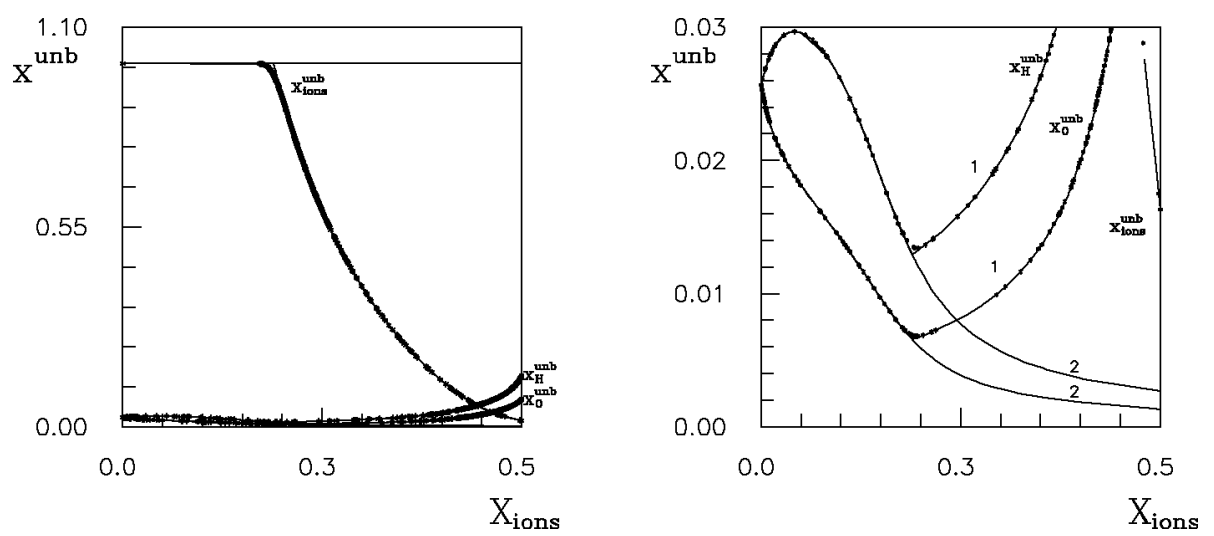

Figure 3. $x^{u n b}, X_{\text {ions }}$ constant - $\eta$ slices of the three-component aqueous-ionic mixture. Different curves correspond to the different fractions of unbonded $\operatorname{sites}\left(x_{H}^{u n b}, x_{O}^{u n b}\right.$, $\left.x_{i o n s}^{u n b}\right)$. The right figure - an enlarged view of $x_{H}^{u n b}$ and $x_{O}^{u n b}$ - curves. The curves 1 correspond to the case when ion dimerization is taken into account, the curves 2 - to the model without interionic association. Asterisks denote smoothed curve. The solid line represents the curve with the cusp which needs smoothing.
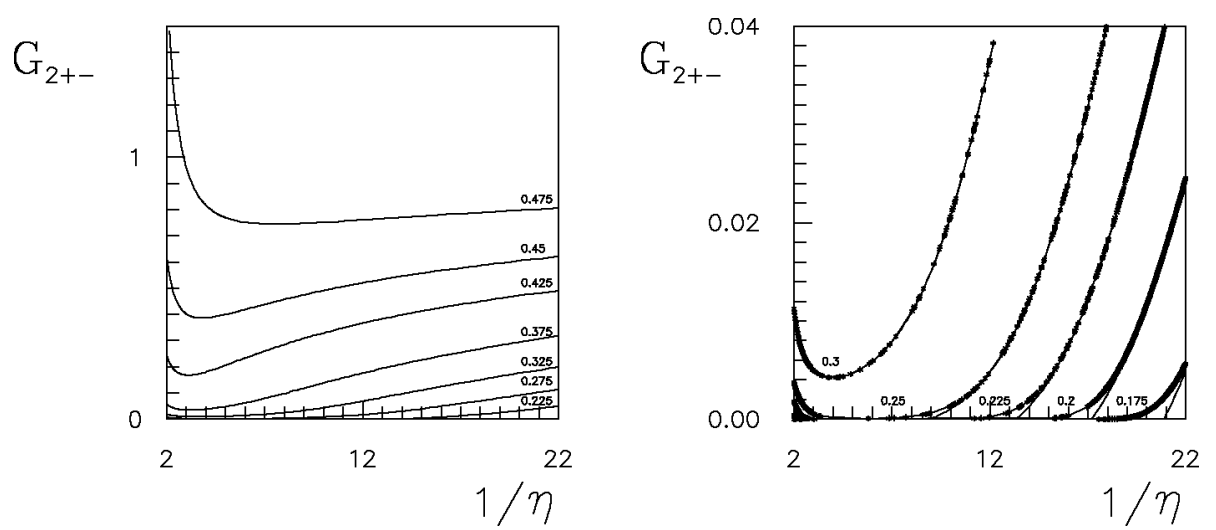

Figure 4. The $g_{2 p n}$, vs $1 / \eta$ dependence for the different mole fractions of ions in the mixture. The right figure presents an enlarged view of the smoothing area (asterisk curve). The solid line represents the curve with the cusp which needs smoothing.

with those presented above in 4 and 5 . In the range of ion concentration $X_{\text {ions }} \leq 0.3$ in the intermediate area of $\eta^{-1} g_{+-}=0$, what means $x_{i o n s}^{u n b}=1$, 
and there is no ion dimerization, since all ions are fully clung by water molecules.
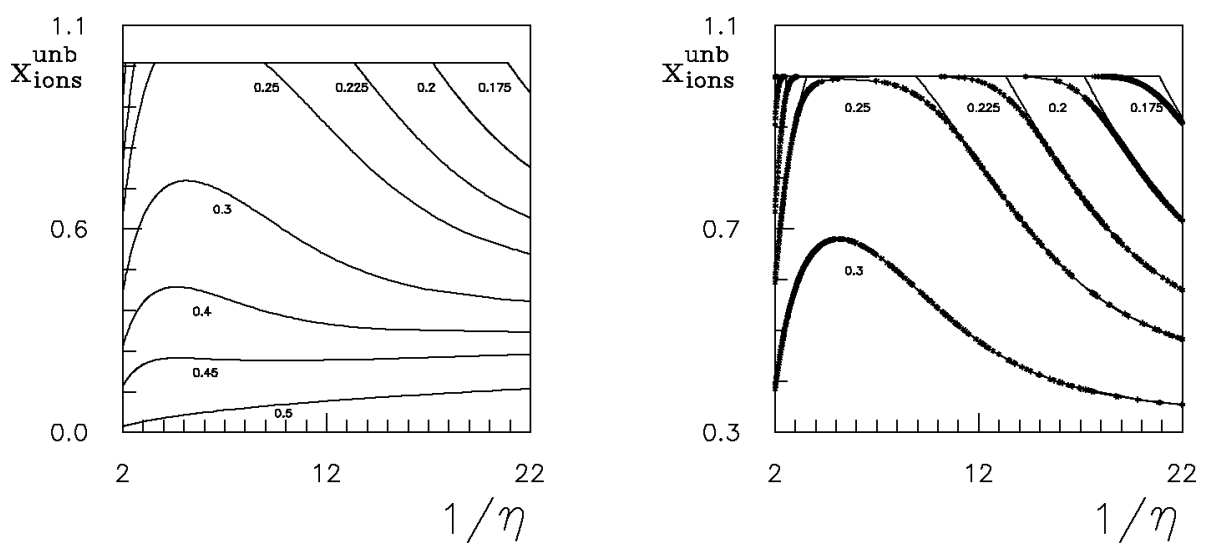

Figure 5. The development of $x_{i o n s}^{u n b}$ vs. $1 / \eta$ for the different mole fractions of ions. On the right figure the smoothed curves (with asterisks) are shown. The solid line represents the curve with the cusp which needs the smoothing.
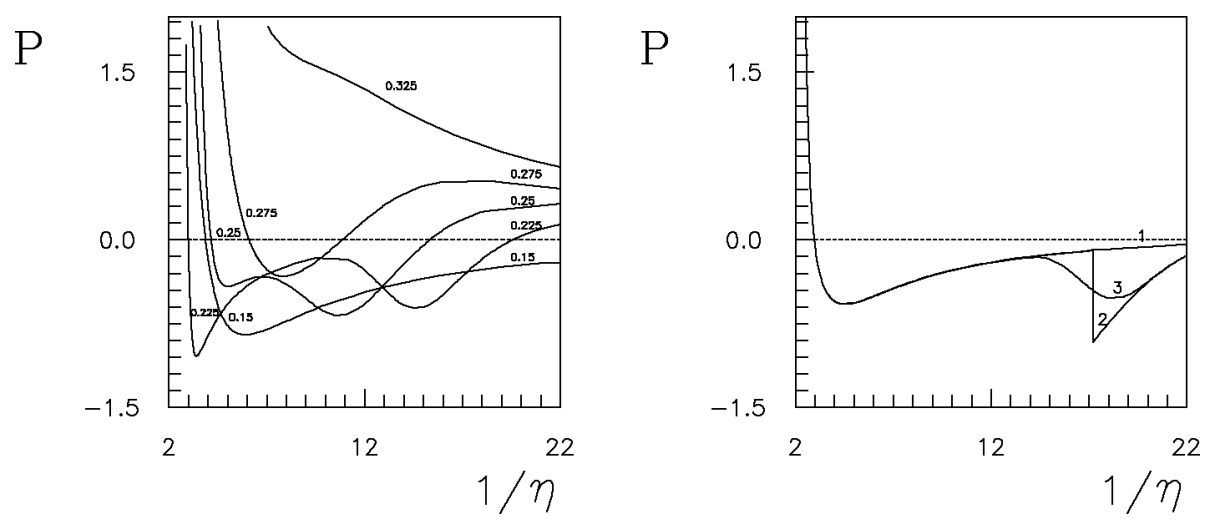

Figure 6 . The development of pressure vs $1 / \eta$ for the different mole fractions of ions in mixture. On the right figure: The 1 curve corresponds to the case without ion dimerization.

The 2,3 - curves describe the system with ion dimerization presented;

The third curve represents the smoothed version.

The pressure, calculated from (2.25) is plotted against $1 / \eta$ at different mole fraction of ions in figure 6 . With increasing of ion concentration each water molecule becomes a connecting-link between ions in the solvation network. If the number of water molecules becomes small enough to ensure the infinite solvation cluster, the phase transition to the disordered gas phase occurs. 
Let us note that the studied model is just a reference system for the ionic-aqueous system. Therefore to consider electrostatic interactions, what is the subject of further investigations, is of great interest.

Appendix. The expression for the $K_{i j}$ - coefficients in the case of the square and quadratic well of site-site potential.

Square well potential $\Phi_{i j}\left(z_{i j}\right)=U_{0 i j}$.

$$
\begin{gathered}
K_{i j}=\frac{\pi}{6 d_{i} d_{j}}\left(e^{-\beta U_{0 i j}}-1\right) \int_{0}^{L_{i j}}\left(3 \sigma_{a b}+s\right)\left(l_{i j}-L_{i j}+s\right) s^{2} d s ; \\
K_{i j}=\frac{\pi\left(e^{-\beta U_{0 i j}}-1\right)\left(\left(L_{i j}+5 \sigma_{a b}\right)\left(5 l_{i j}-L_{i j}\right)-5 l_{i j} \sigma_{a b}\right) L_{i j}{ }^{3}}{120 d_{i} d_{j}} .
\end{gathered}
$$

Quadratic well potential $\Phi_{i j}\left(z_{i j}\right)=U_{0 i j}+U_{1 i j}\left(z_{i j}-z_{0 i j}\right)^{2}$.

$$
\begin{gathered}
K_{i j}=\frac{\pi}{6 d_{i} d_{j}} \int_{0}^{L_{i j}}\left(e^{-\beta U_{0 i j}+U_{1 i j}\left(s+l_{i j}-L_{i j}-z_{0 i j}\right)^{2}}-1\right) * \\
*\left(3 \sigma_{a b}+s\right)\left(l_{i j}-L_{i j}+s\right) s^{2} d s
\end{gathered}
$$

Let us introduce the following substitution of the variables $y=s+l_{i j}-$ $L_{i j}-z_{0 i j}$, where

$$
\begin{gathered}
l_{i j}-L_{i j}=M=\sigma_{a b}-d_{a}^{\alpha}-d_{b}^{\beta} ; \quad B=M-z_{0 i j} ; \\
y=s+B ; \quad l_{i j}-z_{0 i j}=l \\
K_{i j}=\frac{\pi}{6 d_{i} d_{j}} \int_{B}^{L_{i j}+B}\left(e^{-\beta\left(U_{0 i j}+U_{1 i j} y^{2}\right)}-1\right) * \\
*\left(3 \sigma_{a b}-B+y\right)(M-B+y)(s+B)^{2} d y .
\end{gathered}
$$

After integrating over $y$ we get the following expression:

$$
\begin{gathered}
K_{i j}=e^{-\beta U_{0 i j}}\left\{\left[-\frac{l^{3}}{2 \beta{U_{1 i j}}^{2}}+\frac{l^{2}(2 B-R)}{2 \beta U_{1 i j}}\right.\right. \\
\left.-l\left(\frac{3}{4 \beta^{2} U_{1 i j}{ }^{2}}+\frac{B^{2}+2 B R+Q}{2 \beta U_{1 i j}}\right)+\frac{2 B-R}{2 \beta^{2} U_{1 i j}{ }^{2}}+\frac{B^{2} R+2 B Q}{2 \beta U_{1 i j}}\right] e^{-\beta U_{1 i j} l^{2}} \\
+\left[\frac{3}{8 \beta^{2} U_{1 i j}{ }^{2}}+\frac{B^{2}+2 B R+Q}{4 \beta U_{1 i j}}+\frac{B^{2} Q}{2}\right] \sqrt{\frac{\pi}{\beta U_{1 i j}{ }^{2}}}\left[\operatorname{erf}\left(\sqrt{\beta U_{1 i j}} l\right)\right. \\
\left.\left.-\operatorname{erf}\left(\sqrt{\beta U_{1 i j}} B\right)\right]-\left[-\frac{B^{2} R}{\beta U_{1 i j}}-\frac{B Q}{2 \beta U_{1 i j}}+\frac{B-2 R}{4 \beta^{2} U_{1 i j}{ }^{2}}\right] e^{-\beta U_{1 i j} B^{2}}\right\}
\end{gathered}
$$




$$
-\sigma_{a} b M L_{i j}^{3}+\frac{\left(3 \sigma_{a} b+M\right) L_{i j}^{4}}{4}+\frac{L_{i j}^{5}}{5}
$$

here

$$
\begin{aligned}
& R=2 B-M-3 \sigma_{a b}, \\
& Q=(B-M)\left(B-3 \sigma_{a b}\right), \\
& \operatorname{erf}(r)=\text { int. }
\end{aligned}
$$

\section{References}

[1] Ichiye T., Haymet A.D.J. Integral equation theory of ionic solution. // J. Chem. Phys., 1990, vol. 93, p. 8954-8971.

[2] Vlacy V., Ichiye T., Haymet A.D.J. Symmetric associating electrolytes: GCMC simulations and integral equation theory. // J. Am. Chem. Soc., 1991, vol. 113, No 4, p. 1077-1089.

[3] Wertheim M.S. Fluids with highly directional attractive forces. 1. Statistical thermodynamics. // J. Stat. Phys., 1984, vol. 35, No 1/2, p. 19-34; Wertheim M.S. Fluids with highly directional attractive forces. 2. Thermodynamic perturbation theory and integral equations. // J. Stat. Phys., 1984, vol. 35 , No $1 / 2$, p. 35-47.

[4] Wertheim M.S. Fluids with highly directional attractive forces. 3. Multiple attraction sites. // J. Stat. Phys., 1986, vol. 42, No 3/4, p. 459-476; Wertheim M.S. Fluids with highly directional attractive forces. 4. Equilibrium polymerization. // J. Stat. Phys., 1986, vol. 42, No 3/4, p. 477-492.

[5] Yukhnovskii I.R., Holovko M.F. Statistical theory of classical equilibrium systems. Kiev, Naukova Dumka, 1980.

[6] Kalyuzhnyi Yu.V., Stell G. On the Effect of Association in Fluids with Spherically Symmetric Interactions. I.Cluster Expansions and Integral Equations. // Mol. Phys., 1993, vol. 78, No 4, p. 1247-1261.

[7] Kolafa J., Nezbeda I. Monte Carlo simulation on primitive models of water and methanol. // Mol. Phys., 1987, vol. 61, No 1, p. 161-175; Kolafa J., Nezbeda I. Primitive models of associated liquids. Equation of state, liquidgas phase transition, and percolation threshold. // Mol. Phys., 1991, vol. 72, No 4 , p. 777-785.

[8] Nezbeda I., Kolafa J., Kalyuzhnyi Yu.V. Primitive model of water. 2. Theoretical results for the structure and thermodynamic properties. // Mol. Phys., 1989, vol. 68, No 4, p. 143; Nezbeda I., Iglesias-Silva G.A. Primitive model of water. 3. Analytic theoretical results with anomalies for the thermodynamic properties. // Mol. Phys., 1990, vol. 69, No 4, p. 767-774.

[9] Holovko M.F., Antonevych O.P. // Ukr. Fiz. Zhurn., submitted (in Ukrainian).

[10] Holovko M., Protsykevich I. The reference system of the highly asymmetric electrolyte solutions: the analytical treatment. // J. Chem. Phys., submitted.

[11] Heinzinger K., Palinkas G. Computer simulations of ion-solvent systems in the chemical physics of solvation. Part A. Theory of solvation. Amsterdam, Elsevier, 1985. 


\title{
АСОЦІАТИВНА БАЗИСНА МОДЕЛЬ У СТАТИСТИЧНІЙ ТЕОРІЇ ІОННО-ВОДНИХ РОЗЧИНІВ
}

\author{
М.Ф.Головко, А.П.Антоневич
}

\begin{abstract}
Запропонована нова базисна модель іонно-водного розчину. Розглянуто трисортний випадок. Один із сортів моделює воду і вмішає чотири силові центри з короткосяжною притягальною взаємодією, які відповідають за утворення сітки водневих зв'язків. Інші сорти моделюють катіони і аніони і містять один притягувальний силовий центр, який забезпечує врахування міжіонної димеризації. Для опису ефектів сольватації використано спеціальну форму асоціативної взаємодії між молекулами води і іонами. Вважається, що кожний силовий центр на молекулі води може лише однократно зв'язуватися з іоном, в той час як іон може асоціативне взаємодіяти з багатьма молекулами води. Кількість молекул води, взаємодіючих із одним іоном, залежить лише від геометрії взаємодії. Для даної моделі отримані результати для концентрації незайнятих силових центрів, вільної енергії і тиску системи. Фазовий перехід газ-сітка водневих зв'язків, який характерний для чистої води, зникає при зростанні іонної концентрації.
\end{abstract}

